\title{
The effect of knowledge and expectations on adherence to and persistence with antidepressants
}

This article was published in the following Dove Press journal:

Patient Preference and Adherence

6 May 2016

Number of times this article has been viewed

\section{Sophie Claire Woodward Bonnie Jayne Bereznicki Juanita Louise Westbury Luke Ryan Elliot Bereznicki \\ Pharmacy, School of Medicine, University of Tasmania, Hobart, TAS, Australia}

Purpose: Adherence to and persistence with antidepressants are often suboptimal. However, little is known about how patient knowledge and outcome expectations may influence antidepressant adherence and persistence.

Method: Individuals who had been prescribed their first antidepressant to treat depression in the preceding 6 months were recruited to an online survey via Facebook. Knowledge, education received, and initial outcome expectations were analyzed for associations with persistence and adherence.

Results: Two hundred and twenty surveys were analyzed. A total of 117 participants had taken their antidepressant for at least 3 months; another 25 had never started or stopped after $<3$ months without consulting their doctor. Differences in expectations and various educational messages among persistent and nonpersistent participants were identified. Having received the instruction "don't stop it without checking with your doctor" was a significant independent predictor of persistence (odds ratio $[\mathrm{OR}]=5.9,95 \%$ confidence interval $[\mathrm{CI}]=1.4-24.5$ ). At the time of the survey, $82.7 \%$ of participants were taking an antidepressant and $77.9 \%$ were adherent. Significant independent predictors of adherence were a greater age $(\mathrm{OR}=1.1,95 \% \mathrm{CI}=1.0-1.2)$, knowledge $(\mathrm{OR}=1.6,95 \% \mathrm{CI}=1.1-2.3)$, being informed of common side effects $(\mathrm{OR}=5.5,95 \%$ $\mathrm{CI}=1.1-29.0)$, and having discussed ways to solve problems $(\mathrm{OR}=3.9,95 \% \mathrm{CI}=1.1-14.5)$.

Conclusion: Improving outcome expectations and particular educational messages may increase adherence and persistence. Greater knowledge may enhance adherence. Further investigation is warranted to determine whether a focus on these simple educational messages will improve outcomes in patients who commence an antidepressant

Keywords: counseling, Facebook, depression, education

\section{Introduction}

Persistence with and adherence to antidepressants are typically poor, so there remain substantial opportunities for improvement. ${ }^{1}$ Adherence is the extent that a person's medication-taking behavior corresponds with agreed recommendations from a health professional in terms of timing, dosage, and frequency. ${ }^{2}$ Persistence is a measure of how long a patient continues with the treatment, compared to the prescribed duration. ${ }^{2}$ Discontinuing an antidepressant early or taking it inconsistently increases the risk of relapse or recurrence of depression. ${ }^{3}$

There is usually a delay of 1-2 weeks before some response may be seen from an antidepressant and 6 weeks or more for full benefit. ${ }^{4}$ The STAR*D trial found that, while approximately one-third of patients experienced remission with the first antidepressant prescribed, trials of up to four antidepressants were required to achieve a
Correspondence: Luke Ryan Elliot Bereznicki

Pharmacy, School of Medicine, University of Tasmania, Private Bag 26, Hobart,

TAS 700I, Australia

Tel +61362262195

Fax +6I 362262870

Email luke.bereznicki@utas.edu.au
Patient Preference and Adherence 2016:10 76I-768

761

Dovepress

http://dx.doi.org/10.2147/PPA.S99803 (c) (1) $\odot 2016$ Woodward et al. This work is published and licensed by Dove Medical Press Limited. The full terms of this license are available at https://www.dovepress.com/terms.php (c) hereby accept the Terms. Non-commercial uses of the work are permitted without any further permission from Dove Medical Press Limited, provided the work is properly attributed. For permission for commercial use of this work, please see paragraphs 4.2 and 5 of our Terms (https://www.dovepress.com/terms.php). 
cumulative remission rate of $67 \% .^{5}$ Patients starting on an antidepressant should be informed about the likely delay in efficacy and that a change in agent may be required. Patients should be reviewed regularly for efficacy, adverse effects, adherence, and persistence.

Once stabilized on an effective antidepressant, it is recommended that it should be continued for at least 6-12 months after the initial episode of depression. ${ }^{4}$ However, one study found that only $44.3 \%$ of participants were still taking their antidepressant 6 months after the initial prescription. ${ }^{1}$ Of these, $63.1 \%$ discontinued their antidepressant without involving their doctor, and only $55.6 \%$ of participants were considered adherent. ${ }^{1}$ Another study found that only $19 \%$ of participants stayed within the guideline recommendations of how the antidepressant should be taken. ${ }^{6}$ Some patients do not even start their antidepressant, with one-quarter in one study either not starting the medication or discontinuing within 2 weeks. $^{7}$

Possible factors that may influence adherence and persistence include patient knowledge about antidepressants and depression, and patient expectations about the treatment outcome. Patients seem to have varying beliefs, concerns, and misconceptions that may influence their use of antidepressants. ${ }^{8-13}$ For example, the study by Warden et al. ${ }^{14}$ found that patients' initial concerns about possible side effects affected persistence. Another study by this author found that negative attitudes about psychiatric medications were linked with poor persistence at 12 months. ${ }^{15}$ A study by Anderson et al analyzed qualitative data on patient experiences of starting an antidepressant. The approach by the clinician and patients' involvement were reported by patients as influencing whether they took their antidepressant. ${ }^{13}$

Providing accurate and tailored education about antidepressants is likely to assist patients in taking their antidepressants correctly and safely. While educational interventions alone do not appear to result in improved adherence, ${ }^{16,17}$ patients do indicate a desire for more information than is currently being provided, ${ }^{18-20}$ and other studies have found a link between educational messages and persistence. ${ }^{21,22}$ Patient knowledge does not seem to have been studied explicitly in this context. Therefore, research investigating the effect patient knowledge on depression and antidepressants may have on persistence and adherence is warranted, along with further examination of the links that adherence and persistence have with educational messages. This information will assist health professionals to determine their approach when counseling.

There is also a paucity of studies focusing on patient outcome expectations regarding antidepressant treatment.
Researchers have generally indicated a link between more positive initial outcome expectations and a greater response to treatment. ${ }^{23-25}$ However, they have not looked closely at adherence or persistence. Therefore, there is considerable value in studying the possible effect of pretreatment expectations on adherence and persistence in a clinical setting.

The aim of this study was to investigate the relationships outcome expectations, knowledge, and educational messages received may have with adherence to and persistence with antidepressants in patients who have recently initiated antidepressant therapy.

\section{Methods}

Participants were recruited to an online survey using Facebook, Inc ${ }^{\mathrm{TM}}$, from March 12, 2014 to June 15, 2014. A paid advertisement targeted Australian users over 18 years of age. A Facebook page was also created to generate a status in order to share the survey freely with the users. A prize of an Apple ${ }^{\circledR}$ iPad mini was used as an incentive to participate. Participants were eligible if they were aged over 18 years, residing in Australia, and had been prescribed their first antidepressant to treat depression in the preceding 6 months. This was regardless of whether they were currently taking an antidepressant.

The survey asked for the age, sex, current antidepressant taking status, the date on which the antidepressant was started, and, where relevant, the date it was stopped. If participants had switched, stopped, or never started their antidepressant, they were directed to extra questions.

Outcome expectations were measured using a modified version of the Credibility and Expectancy Questionnaire. This was first used in $1972^{26}$ and validated in 2000, showing good internal consistency and test/retest reliability. ${ }^{27}$ Rutherford et al modified this questionnaire for their study, choosing the two questions that measured expectancy. ${ }^{24}$ One question measured the expected likelihood of improvement, and the other the expected magnitude of improvement. ${ }^{24}$ The expectancy score was derived from the sum of these two questions. ${ }^{24}$ Participants were asked to think back to when they were first prescribed their antidepressant and what they thought at this time so that the answers would approximate their initial outcome expectations.

Knowledge was measured using a shortened version of the patient multiple-choice knowledge test of depression and its treatments, developed and psychometrically tested by Gabriel and Violato. ${ }^{28}$ The original questionnaire contained 27 questions; this was shortened to seven for the purposes of this study. The seven questions chosen included a question 
from each component of knowledge about depression and antidepressants that the original researchers assessed. The total number of correct answers gives a knowledge score. ${ }^{28}$ Educational messages received by the participants were also assessed using a questionnaire used by Lin et al with slight modifications. ${ }^{21}$ Participants were asked to think back to the information originally provided by their doctor or pharmacist and whether particular topics or instructions had been covered.

Adherence was measured by the Antidepressant Adherence questionnaire that Gabriel and Violato adapted from the Morisky Medication Adherence Questionnaire. ${ }^{29}$ Participants currently taking an antidepressant were asked to think back over the past 4 weeks to determine the number of times he or she missed the medication. ${ }^{29}$ Participants were classified as being nonadherent if they had missed their medication, for any reason, five or more times over the past 4 weeks. ${ }^{29}$

It was estimated that at least 384 patients needed to be surveyed to ensure that the results were generalizable to the $\sim 1$ million Australians with depression. ${ }^{30}$ This recruitment target was based on a sample size calculation, using data for the total Australian prevalence of depression, with a $95 \%$ confidence interval (CI) and a 5\% margin of error. ${ }^{30,31}$

Variables were analyzed to identify predictors of adherence and persistence. Persistence was analyzed by considering participants who had taken their antidepressant for 3 months or more to be persistent and those who never started or who had stopped after $<3$ months without consulting their doctor to be nonpersistent. Participants who were still taking an antidepressant but who had been taking it for $<3$ months were excluded from this aspect of the analysis. Adherence was analyzed for participants currently taking an antidepressant who had an adherence classification.

All variables were entered into SPSS Version 21 (IBM Corporation, Armonk, NY, USA). Age and sex of the participant, expectation scores, knowledge scores, and educational messages were tested against adherence and persistence. Categorical variables were analyzed using the chi-square test for independence (with Yates continuity correction), parametric continuous variables were analyzed using independentsamples $t$-tests, and nonparametric continuous variables were analyzed using the Mann-Whitney $U$-test. Pearson correlation was used to compare two parametric continuous variables. Logistic regression models were performed on the univariate predictors, with $P<0.1$ used as a threshold for entry into the model. A significance level of $P<0.05$ was used for all statistical procedures. Any missing responses to questions were excluded from the applicable analyses.
This study was approved by the Tasmanian Social Sciences Human Research Ethics Committee on December 10, 2013 (reference number H0013623). An information page was included at the start of the survey. This informed potential participants about the risks and benefits of the study and explained that non-identifiable, combined results may be submitted for publication. All participants were 18 years of age or older. By submitting the survey, participants provided their implied consent.

\section{Results}

A total of 238 patients completed the online survey, of which $220(92.4 \%)$ responses were usable (Figure 1). The cost of the recruitment strategy through Facebook advertising averaged $\$ 6.25$ per response.

A high proportion of respondents were young ( $\leq 25$ years old), and the majority of them were women, as shown in Table 1. The majority of participants were still taking an antidepressant $(82.7 \%)$ at the time of the survey. Of the 181 participants with an adherence classification, 22.1\% reported being nonadherent.

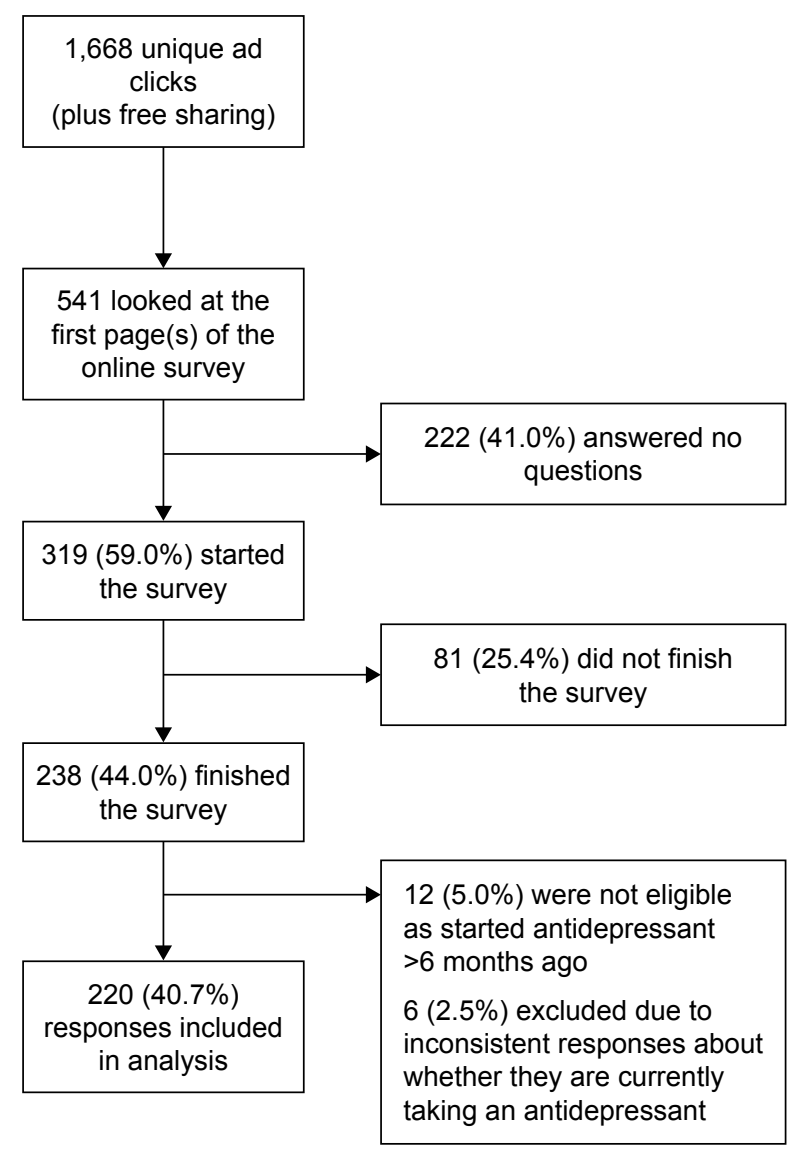

Figure I Participant flowchart. 
Table I Participant characteristics

\begin{tabular}{ll}
\hline Parameter & $\begin{array}{l}\text { Number (\%) } \\
\text { of participants } \\
\text { (N=220) }\end{array}$ \\
\hline Median age in years (range) & $23(18-7$ I) \\
Sex & $50(22.7)$ \\
Male & $170(77.3)$ \\
Female & $182(82.7)$ \\
Participants still on an antidepressant & $166(75.5)$ \\
Have continued original antidepressant & $16(7.3)$ \\
Have switched antidepressants & \\
Time since starting antidepressant & $30(13.6)$ \\
0-I months & $46(20.9)$ \\
I-3 months & $106(48.2)$ \\
3-6 months & $141(77.9)$ \\
Adherence for those still taking an antidepressant & \\
Adherent & $40(22.1)$ \\
Not adherent & $38(17.3)$ \\
Participants not taking an antidepressant & $7(3.2)$ \\
Never started the prescribed antidepressant & $31(14.1)$ \\
Have stopped the antidepressant & $5(2.3)$ \\
Duration of treatment before antidepressant was stopped \\
0-I months & $15(6.8)$ \\
I-3 months & $11(5.0)$ \\
3-6 months & \\
\hline Notes: N totn &
\end{tabular}

Notes: $\mathrm{N}=$ total number of participants analyzed. ${ }^{\mathrm{a}}$ One participant chose not to answer this question.

Table 2 details the reasons participants gave for switching, never starting, or stopping their antidepressant. Participants who had switched antidepressants frequently responded that they had experienced adverse effects $(43.8 \%)$ or that the initial antidepressant was not working (75.0\%). Participants who never started their antidepressant cited concerns about possible adverse effects $(57.1 \%)$ and a belief that they did not think they needed to be on an antidepressant (57.1\%), most commonly.

Participants who had stopped taking an antidepressant did so because of feeling better (16.1\%), experiencing adverse effects $(35.5 \%)$, the lack of efficacy $(48.8 \%)$, or concerns about dependence (19.4\%). Only three (9.7\%) discontinued their antidepressant with their doctor's involvement, with two of these participants discontinuing after $<3$ months. Fourteen $(45.2 \%)$ had since told their doctor, but the remainder had not informed their doctor that they had stopped their medication.

The responses of 142 participants were available for the analysis of persistence. One hundred and seventeen participants $(82.4 \%)$ reported taking their antidepressant for at least 3 months, while 25 (17.6\%) had never started or stopped after $<3$ months without consulting their doctor and were considered to be nonpersistent. Predictors of persistence from the analysis of these participants are shown in Table 3.

Participants who were classified as being persistent had significantly greater mean expectation scores than those who had poor persistence ( $11.5 \pm 3.6$ vs $7.4 \pm 4.1$, respectively; $t=4.8, P<0.001)$. Seven educational messages were found to be significantly associated with persistence, and one showed a trend toward significance. Persistent participants had a greater median age than nonpersistent participants, with a trend toward significance (median age 23, range 18-71 vs 22 , range $18-61$, respectively; $U=1,122.5, P=0.08$ ). There was no significant association with persistence for knowledge scores $(t=0.9, P=0.332)$ or $\operatorname{sex}\left(x^{2}=0.03, d f=1, P=0.86\right)$.

The multiple variable logistic regression model for persistence was statistically significant, $x^{2}(10, \mathrm{~N}=108)=30.0$, $P=0.001$, explained between $24.3 \%$ and $40.9 \%$ of variance in persistence, and correctly classified $88.0 \%$ of cases. The educational instruction "don't stop it without checking with your doctor" was identified as a significant independent predictor of persistence ( $\mathrm{OR}=5.9,95 \% \mathrm{CI}=1.4-24.5)$.

A total of 181 participants were still taking their antidepressant at the time of the survey and were assessed for adherence, with $22.1 \%$ of these classified as nonadherent. Table 4 contains the predictors of adherence for these participants. Adherent participants were significantly older than nonadherent participants (median age 28, range 18-71 vs 21 , range $18-57$, respectively; $U=1,872.5, P=0.002$ ). Participants who were adherent also had significantly greater mean expectation scores than those who were nonadherent

Table 2 Reasons given for switching, stopping, or never starting the prescribed antidepressant

\begin{tabular}{|c|c|c|c|}
\hline Reason $^{a}$ & $\begin{array}{l}\text { Switched, } \\
\text { n (\%) }(n=16)\end{array}$ & $\begin{array}{l}\text { Stopped, } \\
\text { n (\%) }(n=3 \text { I) }\end{array}$ & $\begin{array}{l}\text { Never started, } \\
n(\%)(n=7)\end{array}$ \\
\hline I was worried about possible adverse effects & I (6.25) & $\mathrm{I}(3.2)$ & $4(57.7)$ \\
\hline I experienced adverse effect(s) & $7(43.8)$ & II (35.5) & - \\
\hline I didn't think I needed to be on an antidepressant & - & $\mathrm{I}(3.2)$ & $4(57.7)$ \\
\hline I felt better & - & $5(16.1)$ & I (I4.3) \\
\hline It wasn't working for me & $12(75)$ & $15(48.4)$ & - \\
\hline I was worried about becoming too dependent on it & - & $6(19.4)$ & $2(28.6)$ \\
\hline Other & $2(12.5)$ & $6(19.4)$ & - \\
\hline
\end{tabular}

Notes: $n=$ number of participants. aParticipants could select more than one reason, so percentages do not add up to $100 \%$. 
Table 3 Predictors of persistence

\begin{tabular}{|c|c|c|c|c|c|c|c|c|}
\hline \multirow[t]{3}{*}{ Parameter } & \multicolumn{4}{|c|}{ Univariate analysis } & \multicolumn{4}{|c|}{ Multivariate analysis } \\
\hline & \multirow{2}{*}{$\begin{array}{l}\text { All } \\
\text { participants } \\
\text { analyzed }^{a} \\
(n=I 42)\end{array}$} & \multirow{2}{*}{$\begin{array}{l}\text { Persistent } \\
(n=|| 7)^{b}\end{array}$} & \multirow[t]{2}{*}{$\begin{array}{l}\text { Nonpersistent } \\
(\mathrm{n}=25)^{\mathrm{b}}\end{array}$} & \multirow[t]{2}{*}{$P$-value* } & \multirow[t]{2}{*}{$\begin{array}{l}\text { Odds } \\
\text { ratio }\end{array}$} & \multicolumn{2}{|c|}{$\begin{array}{l}95 \% \\
\text { confidence } \\
\text { interval }\end{array}$} & \multirow[t]{2}{*}{$P$-value* } \\
\hline & & & & & & Lower & Upper & \\
\hline Median age in years (range) & & $23(|8-7|)$ & $22(|8-6|)$ & 0.076 & 1.0 & 1.0 & 1.1 & 0.205 \\
\hline Expectation score $( \pm S D)$ & & $11.5( \pm 3.6)$ & $7.4( \pm 4.1)$ & $<0.001$ & 1.2 & 1.0 & $\mathrm{I} .4$ & 0.100 \\
\hline \multicolumn{9}{|l|}{ Educational message received, $n$ (\%) } \\
\hline How the medication works & $109(76.8)$ & $95(84.8)$ & $14(60.9)$ & 0.018 & 1.8 & 0.4 & 8.9 & 0.474 \\
\hline $\begin{array}{l}\text { Told how long it should take to start having a noticeable } \\
\text { effect and told a couple of weeks or a month or so }\end{array}$ & $113(79.6)$ & $99(86.8)$ & $14(58.3)$ & 0.003 & 3.5 & 0.4 & 35.0 & 0.282 \\
\hline Don't stop without checking with your doctor ${ }^{c}$ & $104(73.2)$ & $95(82.6)$ & $9(40.9)$ & $<0.001$ & 5.9 & 1.4 & 24.5 & 0.014 \\
\hline Common adverse effects & $113(79.6)$ & $97(85.1)$ & $16(64.0)$ & 0.030 & 0.3 & 0.02 & 3.2 & 0.273 \\
\hline How to manage minor side effects & $66(46.5)$ & $60(54.5)$ & $6(26.1)$ & 0.024 & 0.6 & 0.1 & 3.2 & 0.528 \\
\hline What to do if experience major side effects & $87(61.3)$ & $76(67.9)$ & II (45.8) & 0.071 & 1.3 & 0.2 & 7.1 & 0.776 \\
\hline When or how long might have side effects & $67(47.2)$ & $60(55.0)$ & $7(29.2)$ & 0.038 & 1.7 & 0.3 & 11.4 & 0.573 \\
\hline What to do if have questions about the use of the medicine & $100(70.4)$ & $88(78.6)$ & $12(50.0)$ & 0.009 & 2.7 & 0.4 & 17.3 & 0.288 \\
\hline
\end{tabular}


after $<3$ months who did so without consulting their doctor $(n=25)$. bome percentages may be out of a smaller denominator due to missing responses. 'Significant independent predictor. $* P<0.05$ is considered significant.

(11.9 \pm 3.6 vs $10.1 \pm 3.9$, respectively; $t=2.8, P=0.006$ ), although the difference was small. Adherent participants had significantly better mean knowledge scores than those who were nonadherent $(5.2 \pm 1.5$ vs $4.7 \pm 1.6$, respectively; $t=2.0, P=0.042$ ). Five educational messages were found to be significantly associated with adherence, and four showed a trend toward significance. There was no significant association between the sex of the participant and adherence $\left(x^{2}=0.85, d f=1, P=0.36\right)$.

The multiple variable logistic regression model for adherence was statistically significant, $x^{2}(12, \mathrm{~N}=148)=43.0$, $P<0.001$, explained between $25.2 \%$ and $39.3 \%$ of variance in adherence, and correctly classified $81.8 \%$ of cases. Four independent predictors were identified: higher age ( $\mathrm{OR}=1.1,95 \%$ $\mathrm{CI}=1.0-1.2)$, knowledge score $(\mathrm{OR}=1.6,95 \% \mathrm{CI}=1.1-2.3)$, being informed of common side effects (OR $=5.5,95 \%$ $\mathrm{CI}=1.1-29.0$ ), and having discussed ways to solve problems ( $\mathrm{OR}=3.9,95 \% \mathrm{CI}=1.1-14.5)$.

No correlation was found between knowledge and expectation scores $(r=0.005)$.

\section{Discussion}

Poor persistence with and nonadherence to antidepressants were common in our study participants. The results indicate

Table 4 Predictors of adherence

\begin{tabular}{|c|c|c|c|c|c|c|c|c|}
\hline \multirow[t]{5}{*}{ Parameter } & \multicolumn{4}{|c|}{ Univariate analysis } & \multicolumn{4}{|c|}{ Multivariate analysis } \\
\hline & \multirow{4}{*}{$\begin{array}{l}\text { All } \\
\text { participants } \\
\text { analyzed }^{a} \\
(n=\mid 8 I)\end{array}$} & \multirow{4}{*}{$\begin{array}{l}\text { Adherent } \\
(n=14 I)^{b}\end{array}$} & \multirow{4}{*}{$\begin{array}{l}\text { Nonadherent } \\
(n=40)^{b}\end{array}$} & \multirow{4}{*}{ P-value* } & \multirow{4}{*}{$\begin{array}{l}\text { Odds } \\
\text { ratio }\end{array}$} & \multirow{3}{*}{\multicolumn{2}{|c|}{$\begin{array}{l}95 \% \\
\text { confidence } \\
\text { interval }\end{array}$}} & \multirow[t]{4}{*}{$P$-value* } \\
\hline & & & & & & & & \\
\hline & & & & & & & & \\
\hline & & & & & & Lower & Upper & \\
\hline Median age in years (range) ${ }^{c}$ & & $28(|8-7|)$ & $21(18-57)$ & 0.002 & I.I & 1.0 & 1.2 & 0.002 \\
\hline Expectation score $( \pm S D)$ & & $11.9( \pm 3.6)$ & $10.1( \pm 3.9)$ & 0.006 & I.I & 1.0 & 1.2 & 0.169 \\
\hline Knowledge score $( \pm S D)^{c}$ & & $5.2( \pm I .5)$ & $4.7( \pm 1.6)$ & 0.042 & 1.6 & I.I & 2.3 & 0.010 \\
\hline \multicolumn{9}{|l|}{ Educational message received, $\mathbf{n}(\%)$} \\
\hline How the medication works & 147 (8I.2) & $119(88.8)$ & $28(71.8)$ & 0.018 & 2.5 & 0.7 & 9.5 & 0.181 \\
\hline Asked about prior use of a similar medicine & $129(7 \mid .3)$ & $106(77.4)$ & $23(60.5)$ & 0.060 & 1.0 & 0.3 & 3.6 & 0.949 \\
\hline Common side effects ${ }^{c}$ & $143(79.0)$ & $119(85.6)$ & $24(6 I .5)$ & 0.002 & 5.5 & I.I & 29.0 & 0.044 \\
\hline How to manage minor side effects & $92(50.8)$ & $79(58.1)$ & $13(36.1)$ & 0.031 & 0.4 & 0.1 & 1.5 & 0.180 \\
\hline What to do if experience major side effects & $116(64.1)$ & $98(72.1)$ & $18(46.2)$ & 0.005 & 1.4 & 0.3 & 5.4 & 0.669 \\
\hline Discussed things already doing that are helping & $97(53.6)$ & $81(59.1)$ & $16(40.0)$ & 0.050 & 0.9 & 0.3 & 2.6 & $0.78 \mathrm{I}$ \\
\hline Discussed planning pleasurable activities & $82(45.3)$ & $69(50.4)$ & $13(32.5)$ & 0.070 & 1.4 & 0.4 & 4.5 & 0.590 \\
\hline Discussed ways of solving problems having in life ${ }^{c}$ & $82(45.3)$ & 7I (5I.8) & II (27.5) & 0.011 & 3.9 & I.I & 14.5 & 0.042 \\
\hline Discussed identifying and changing thoughts that get you down & $68(37.6)$ & $58(42.3)$ & $10(25.0)$ & 0.072 & 0.5 & 0.1 & 2.0 & 0.361 \\
\hline
\end{tabular}

Notes: $n=$ number of participants. aParticipants currently taking an antidepressant who had answered the questions pertaining to adherence were included in these analyses. bSome percentages may be out of a smaller denominator due to missing responses. 'Significant independent predictor. $* P<0.05$ is considered significant. 
that improving outcome expectations may increase adherence and persistence, and improving knowledge may improve adherence. Certain specific educational messages were also linked with persistence or adherence.

Persistence among the participants was better than in some studies. ${ }^{1,21,32}$ For example, two other studies found that $38 \%$ and $57 \%$, respectively, stopped within 3 months of initial prescription. ${ }^{1,32}$ Adherence was also greater than other studies have reported. ${ }^{1,33}$ Conversely, the proportion of patients who stopped their antidepressant without involving their doctor was similar to or greater than that reported in previous studies. ${ }^{1,6}$

This study provides new information on the effects of outcome expectations on adherence to and persistence with antidepressants. Previous research has focused more on the effects on treatment outcome from taking antidepressants, with little information on persistence and adherence. ${ }^{24,25}$ While the magnitude in the difference between the mean expectation scores was small, the results are promising. The associations between higher outcome expectations and both persistence and adherence indicate that interventions to improve patients' outcome expectations could be worthwhile.

There has been limited research to date on factors that may influence a patient's expectations about treatment outcome. The current study did not find a link between knowledge and expectations. Possible factors identified previously include more information about the offered treatment, past experiences with medications, and relationships with health care providers. ${ }^{34-36}$ However, the best ways to improve a patient's expectations are unclear. For example, changing the doctor's communication style has not always had an effect on expectations in past studies. ${ }^{23}$ Further research is needed to identify the ways to influence patients' outcome expectations.

Knowledge about depression and antidepressants was an independent predictor of adherence. Studies have found that greater education about antidepressants may give patients more confidence and is associated with an increased use of antidepressants, and that educational messages may be linked to adherence. ${ }^{19,21,22}$ However, multiple studies show only minimal effect of educational interventions alone on adherence. ${ }^{16,17}$ Despite this, the link between knowledge and adherence in this study reiterates the importance of ensuring that patients are knowledgeable about depression and antidepressants as a component of promoting adherence.

This study supports the findings of Lin et al, who found specific educational messages to be linked with persistence (termed "adherence" in their study) after 1 month. ${ }^{21}$ Three of the significant messages were in common with their study: how long the antidepressant should take to start having a noticeable effect and being told a couple of weeks or a month or so; what to do if the person had questions about the use of the medicine; and not to stop the medication without checking with the doctor. The message about time to effect being significant indicates that knowing it will take some time to work may help patients persevere. This aligns with a comment made by a patient in one study who explained that being told it would take 4-6 weeks to start working helped him to not give up on treatment. ${ }^{13}$

The only independent predictor of persistence was advising patients not to stop without telling their doctor, which suggests that this message may effectively discourage patients from stopping on their own, without seeking support. How the medication works and three of the messages about side effects were also significant. Perhaps counter intuitively, the message about how long to expect to continue taking the medication was not related to persistence. Similarly, being told to keep taking the medicine even if starting to feel better was also not related. It could be that these messages play a greater role in persistence later into treatment.

In common with the analysis of persistence, three of the four educational messages about side effects were significantly related to adherence. In particular, communication about common side effects was an independent predictor. The links between communication about side effects and persistence and adherence support the findings from Bull et al, ${ }^{12}$ who found discussion about adverse effects significantly reduced the odds of stopping antidepressant treatment. Similarly, patients in other studies had more confidence if they experienced adverse effects as described, or found adverse reactions more tolerable when they had been informed about them. ${ }^{37,38}$ Other significant messages associated with adherence included how the medication works and discussing ways to solve problems (an independent predictor). Interestingly, being told to take the medication on a daily basis without interruption was not related to adherence.

This analysis of educational messages emphasizes the value of a number of common counseling points to help with adherence, persistence, or both. However, not all of the messages that were or were not significant were predictable. This highlights the possible benefits of considering studies like this one in order to incorporate evidence-based counseling approaches into clinical practice.

There are some potential limitations to this study. The comparatively small proportion of nonpersistent or nonadherent participants may have been due to these 
individuals being less likely to participate. Advertising a prize of an iPad mini through Facebook also had the potential to influence participants and to encourage misleading responses. Additionally, the sample size was less than that calculated, and recruitment through Facebook may have led to a select population that may not fully represent the target population. The combination of these factors may have influenced the observed level of persistence.

There were more women responders, which may be partially explained by a greater rate of having a "depressive episode" in women and a greater utilization of mental health services, as measured in an Australian national survey in $2007 .{ }^{30}$ However, the difference in the number of responders by sex is larger than this explanation alone can account for. Although there were more young responders, the age range responding was wide (18-71), meaning there were still a number of older participants. Location demographic data were not collected, so the spread of respondents across Australia was not analyzed. A possible strength of this novel recruitment strategy is that it may have reached individuals normally missed through standard methods, including those who may have limited contact with health care professionals.

In addition, there were limitations relating to the nature of the survey. The survey relied on participants self-reporting their adherence and persistence, looking at only the past 4 weeks. Furthermore, initial outcome expectations and education received were not measured at the start of treatment. Instead, participants were asked to think back on when they were first prescribed their original antidepressant. Some of the questionnaires were modified slightly. In particular, the knowledge questionnaire was shortened so that the survey would not be overly long. Additionally, clinical outcome was not measured in this study, which meant that the relationships between this and the observed adherence and persistence rates were not analyzed.

While recruitment was specific for patients with depression only, it is possible that patients with other diagnoses participated. Clinical variables such as the severity and duration of illness, specific medications and dosages prescribed, and other treatments patients are on could be looked at in future studies. Despite these potential limitations, a significant strength of this study is that it addresses areas that have received minimal prior study, especially in a clinical setting. Future research could aim to support the study results in other populations, with larger sample sizes.

\section{Conclusion}

In conclusion, given that poor persistence and adherence are often typical of patients taking an antidepressant, the results provide valuable information for researchers and health professionals alike. Future studies could further investigate what influences expectations, which could lead to the development of targeted interventions to improve patients' initial outcome expectations. An immediate implication for clinical practice is guidance on key messages to include when counseling patients starting an antidepressant to attain greater persistence and adherence. Further investigation is warranted to determine whether a focus on these simple educational messages will improve patient outcomes. Overall, the results of this study are encouraging and indicate promising avenues to explore.

\section{Acknowledgments}

The abstract of this paper was presented at the Australasian Pharmaceutical Science Association conference in December 2014 as an oral presentation. The full program, with the abstract included on page 45 , is available at http:// apsa-online.org/files/2014ConferenceProceedings.pdf. The actual paper, however, has never been published and is not being considered for publication elsewhere.

\section{Disclosure}

The authors declare no conflicts of interest in this work.

\section{References}

1. Sawada N, Uchida H, Suzuki T, et al. Persistence and compliance to antidepressant treatment in patients with depression: a chart review. BMC Psychiatry. 2009;9:38.

2. Cramer JA, Roy A, Burrell A, et al. Medication compliance and persistence: terminology and definitions. Value Health. 2008;11(1): 44-47.

3. Pompili M, Serafini G, Del Casale A, et al. Improving adherence in mood disorders: the struggle against relapse, recurrence and suicide risk. Expert Rev Neurother. 2009;9(7):985-1004.

4. Therapeutic Guidelines Limited. Treatment of Depression. Melbourne: eTG complete; 2013

5. Rush AJ, Trivedi MH, Wisniewski SR, et al. Acute and longerterm outcomes in depressed outpatients requiring one or several treatment steps: a STAR*D report. Am J Psychiatry. 2006;163(11): 1905-1917.

6. Hunot VM, Horne R, Leese MN, Churchill RC. A cohort study of adherence to antidepressants in primary care: the influence of antidepressant concerns and treatment preferences. Prim Care Companion J Clin Psychiatry. 2007;9(2):91-99.

7. van Geffen EC, Gardarsdottir H, van Hulten R, van Dijk L, Egberts AC, Heerdink ER. Initiation of antidepressant therapy: do patients follow the GP's prescription? Br J Gen Pract. 2009;59(559):81-87.

8. Brown C, Battista DR, Bruehlman R, Sereika SS, Thase ME, DunbarJacob J. Beliefs about antidepressant medications in primary care patients: relationship to self-reported adherence. Med Care. 2005;43(12): 1203-1207.

9. Chakraborty K, Avasthi A, Kumar S, Grover S. Attitudes and beliefs of patients of first episode depression towards antidepressants and their adherence to treatment. Soc Psychiatry Psychiatr Epidemiol. 2009; 44(6):482-488. 
10. van Geffen EC, Hermsen JH, Heerdink ER, Egberts AC, Verbeek-Heida PM, van Hulten R. The decision to continue or discontinue treatment: experiences and beliefs of users of selective serotonin-reuptake inhibitors in the initial months - a qualitative study. Res Social Adm Pharm. 2011;7(2):134-150.

11. Kessing LV, Hansen HV, Demyttenaere K, Bech P. Depressive and bipolar disorders: patients' attitudes and beliefs towards depression and antidepressants. Psychol Med. 2005;35(8):1205-1213.

12. Bull SA, Hu XH, Hunkeler EM, et al. Discontinuation of use and switching of antidepressants: influence of patient-physician communication. JAMA. 2002;288(11):1403-1409.

13. Anderson C, Kirkpatrick S, Ridge D, Kokanovic R, Tanner C. Starting antidepressant use: a qualitative synthesis of UK and Australian data. BMJ Open. 2015;5(12):e008636.

14. Warden D, Trivedi MH, Wisniewski SR, et al. Identifying risk for attrition during treatment for depression. Psychother Psychosom. 2009; 78(6):372-379.

15. Warden D, Rush AJ, Carmody TJ, et al. Predictors of attrition during one year of depression treatment: a roadmap to personalized intervention. J Psychiatr Pract. 2009;15(2):113-124.

16. Chong WW, Aslani P, Chen TF. Effectiveness of interventions to improve antidepressant medication adherence: a systematic review. Int J Clin Pract. 2011;65(9):954-975.

17. Gilbody S, Whitty P, Grimshaw J, Thomas R. Educational and organizational interventions to improve the management of depression in primary care: a systematic review. JAMA. 2003;289(23):3145-3151.

18. Garfield S, Francis SA, Smith FJ. Building concordant relationships with patients starting antidepressant medication. Patient Educ Couns. 2004;55(2):241-246.

19. Haslam C, Brown S, Atkinson S, Haslam R. Patients' experiences of medication for anxiety and depression: effects on working life. Fam Pract. 2004;21(2):204-212.

20. van Geffen EC, Kruijtbosch M, Egberts AC, Heerdink ER, van Hulten R. Patients' perceptions of information received at the start of selective serotonin-reuptake inhibitor treatment: implications for community pharmacy. Ann Pharmacother. 2009;43(4):642-649.

21. Lin EH, Von Korff M, Katon W, et al. The role of the primary care physician in patients' adherence to antidepressant therapy. Med Care. 1995;33(1):67-74

22. Sun GC, Hsu MC, Moyle W, Lin MF, Creedy D, Venturato L. Mediating roles of adherence attitude and patient education on antidepressant use in patients with depression. Perspect Psychiatr Care. 2011;47(1): 13-22.

23. Rutherford BR, Wager TD, Roose SP. Expectancy and the treatment of depression: a review of experimental methodology and effects on patient outcome. Curr Psychiatry Rev. 2010;6(1):1-10.
24. Rutherford BR, Marcus SM, Wang P, et al. A randomized, prospective pilot study of patient expectancy and antidepressant outcome. Psychol Med. 2013;43:1-8.

25. Sotsky SM, Glass DR, Shea MT, et al. Patient predictors of response to psychotherapy and pharmacotherapy: findings in the NIMH Treatment of Depression Collaborative Research Program. Am J Psychiatry. 1991;148(8):997-1008.

26. Borkovec TD, Nau SD. Credibility of analogue therapy rationales. J Behav Ther Exp Psychiatry. 1972;3(4):257-260.

27. Devilly GJ, Borkovec TD. Psychometric properties of the credibility/ expectancy questionnaire. J Behav Ther Exp Psychiatry. 2000;31(2): 73-86.

28. Gabriel A, Violato C. The development of a knowledge test of depression and its treatment for patients suffering from non-psychotic depression: a psychometric assessment. BMC Psychiatry. 2009;9:56.

29. Gabriel A, Violato C. Knowledge of and attitudes towards depression and adherence to treatment: the Antidepressant Adherence Scale (AAS). $J$ Affect Disord. 2010;126(3):388-394.

30. Australian Bureau of Statistics. National Survey of Mental Health and Wellbeing: Summary of Results, 2007 (4326.0). Canberra: ABS; 2008 .

31. SurveyMonkey Inc [webpage on the Internet]. Survey Sample Size; 2013. Available from: https:/www.surveymonkey.com/mp/samplesize/. Accessed July 22, 2013

32. Lu CY, Roughead E. New users of antidepressant medications: first episode duration and predictors of discontinuation. Eur J Clin Pharmacol. 2012;68(1):65-71.

33. Bulloch AG, Patten SB. Non-adherence with psychotropic medications in the general population. Soc Psychiatry Psychiatr Epidemiol. 2010;45(1):47-56.

34. Dolovich L, Nair K, Sellors C, Lohfeld L, Lee A, Levine M. Do patients' expectations influence their use of medications? Qualitative study. Can Fam Physician. 2008;54(3):384-393.

35. Horvath P. Treatment expectancy as a function of the amount of information presented in therapeutic rationales. J Clin Psychol. 1990; 46(5):636-642.

36. Moses T, Leuchter AF, Cook I, Abrams M. What shapes depressed individuals' pre-treatment expectation in antidepressant clinical trials? Internet J Ment Health. 2007;3(2):1-12.

37. Badger F, Nolan P. Concordance with antidepressant medication in primary care. Nurs Stand. 2006;20(52):35-40.

38. Bollini P, Tibaldi G, Testa C, Munizza C. Understanding treatment adherence in affective disorders: a qualitative study. $J$ Psychiatr Ment Health Nurs. 2004;11(6):668-674.
Patient Preference and Adherence

\section{Publish your work in this journal}

Patient Preference and Adherence is an international, peer-reviewed, open access journal that focuses on the growing importance of patient preference and adherence throughout the therapeutic continuum. Patient satisfaction, acceptability, quality of life, compliance, persistence and their role in developing new therapeutic modalities and compounds to optimize

\section{Dovepress}

clinical outcomes for existing disease states are major areas of interest for the journal. This journal has been accepted for indexing on PubMed Central The manuscript management system is completely online and includes a very quick and fair peer-review system, which is all easy to use. Visit http://www. dovepress.com/testimonials.php to read real quotes from published authors. 